\title{
Molecular Interaction of Bone Marrow Adipose Tissue with Energy Metabolism
}

\author{
Karla J. Suchacki ${ }^{1}$ - William P. Cawthorn ${ }^{1}$
}

Published online: 28 April 2018

(C) The Author(s) 2018

\begin{abstract}
Purpose of Review The last decade has seen a resurgence in the study of bone marrow adipose tissue (BMAT) across diverse fields such as metabolism, haematopoiesis, skeletal biology and cancer. Herein, we review the most recent developments of BMAT research in both humans and rodents, including the distinct nature of BMAT; the autocrine, paracrine and endocrine interactions between BMAT and various tissues, both in physiological and pathological scenarios; how these interactions might impact energy metabolism; and the most recent technological advances to quantify BMAT.

Recent Findings Though still dwarfed by research into white and brown adipose tissues, BMAT is now recognised as endocrine organ and is attracting increasing attention from biomedical researchers around the globe.

Summary We are beginning to learn the importance of BMAT both within and beyond the bone, allowing us to better appreciate the role of BMAT in normal physiology and disease.
\end{abstract}

Keywords Bone marrow adipocytes $\cdot$ Bone marrow adipose tissue $\cdot$ Endocrinology and metabolism

\section{Introduction}

In humans white adipose tissue (WAT) forms in utero and persists throughout life. Upon formation, adipose tissue is highly active and responds rapidly to external and internal cues [1]. Most commonly, adipose tissue is defined as either WAT or brown adipose tissue (BAT) and is found in discrete and defined locations throughout the body. WAT and BAT depots differ both in their developmental origin and function. WAT stores excess energy as triglycerides and, when needed, catabolises these stores to release fatty acids and glycerol. In contrast, BAT expresses thermogenic proteins (e.g. uncoupling protein 1, UCP1) that allow it to dissipate energy through the production of heat [2]. In addition to WAT and BAT, bone

This article is part of the Topical Collection on Molecular Biology of Bone Marrow Fat Adiposity

Karla J. Suchacki

ksuchack@exseed.ed.ac.uk

1 University/British Heart Foundation Centre for Cardiovascular Science, The Queen's Medical Research Institute, University of Edinburgh, Edinburgh EH16 4TJ, UK marrow adipose tissue (BMAT) constitutes over $10 \%$ of total fat mass in lean, healthy humans. BMAT further increases in diverse clinical conditions, including osteoporosis, ageing, type 2 diabetes, and radiotherapy, with recent studies also showing BMAT regulation in mild spastic cerebral palsy, paediatric nonalcoholic fatty liver disease, inflammatory bowel disease, chronic kidney disease and macrodactyly [3-13]. In stark contrast to WAT, BMAT is also increased in caloric restriction and anorexia nervosa. These observations suggest that BMAT has systemic metabolic actions distinct to those of WAT and BAT. Compared to WAT and BAT, knowledge of BMAT formation and function is extremely limited, despite BMAT being identified over a century ago. This is partly due to the challenges inherent in studying a tissue so diffuse and difficult to access. However, in the last decade BMAT has seen increasing attention among several research fields, including metabolism, haematopoiesis, skeletal biology and cancer. Herein, we review the most recent developments of BMAT research in both humans and rodents, including the distinct nature of BMAT; the autocrine, paracrine and endocrine interactions between BMAT and various tissues, both in physiological and pathological scenarios; how these interactions impact energy metabolism; and the most recent technological advances to quantify bone marrow (BM) adiposity (Fig. 1). 


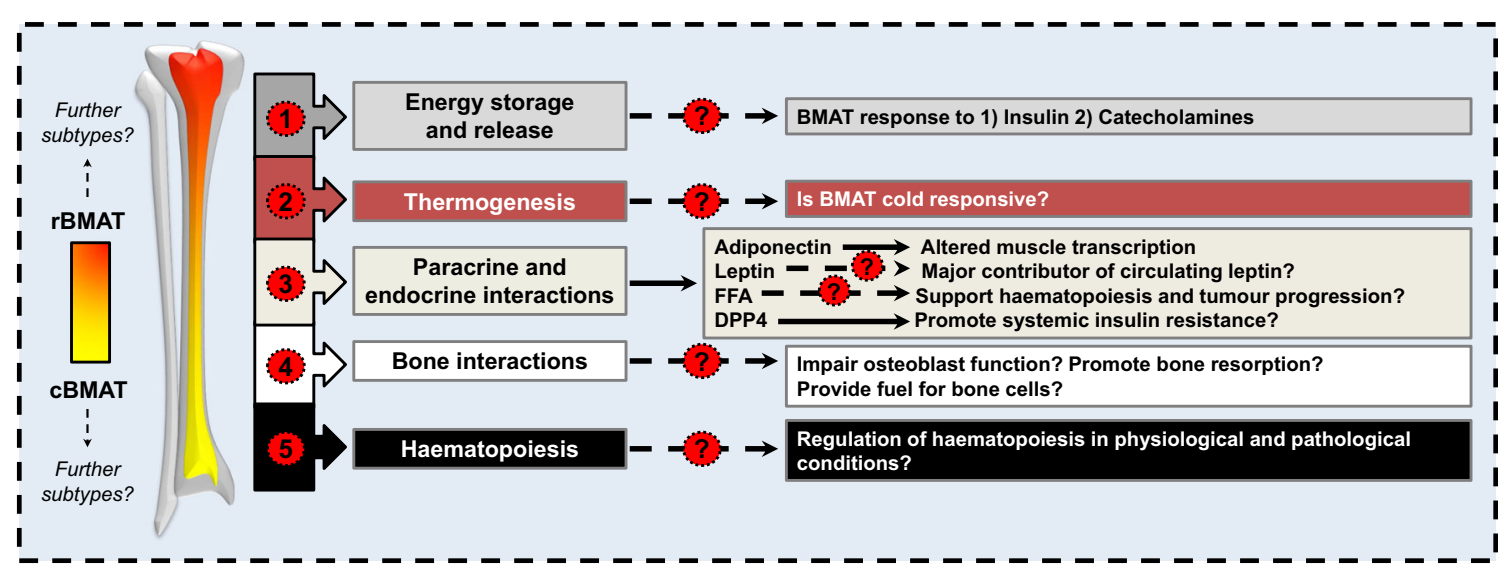

Fig. 1 Unknown functions of bone marrow adipose tissue (BMAT)

Recent efforts have begun to uncover the role of BMAT in energy metabolism, including insulin responsiveness [14••, 15], the response of BMAT to catecholamines [16•], and potential BAT-like characteristics (see 'BMAT - a distinct adipose depot?'). However, it remains unclear to what extent BMAT acts as a site of energy storage and release, how paracrine and endocrine actions of BMAT impact energy metabolism, the ability of BMAT to interact with bone cells, and the role of BMAT in haematopoiesis. These topics are covered in the text.

\section{BMAT—a Distinct Adipose Depot?}

The development of BMAT is a normal physiological process that progresses throughout the lifespan, such that by adulthood (25 years) BMAT occupies 50 to $70 \%$ of the total bone marrow volume [17]. This increase results from the BM undergoing a red-to-yellow conversion occurring in a centripetal fashion [18, 19]. During normal development this red-toyellow marrow conversion is independent of WAT accumulation and slows during adulthood. However, in obesity, vertebral BMAT is positively associated with visceral fat [20], suggesting a relationship between BMAT and WAT development in this context. The conversion of red-to-yellow marrow in rodents also occurs in a similar centripetal pattern and, in both rodents and humans, two distinct populations of BM adipocytes have been described: constitutive BMAT (cBMAT) is situated in the distal long bones and (in rodents) caudal vertebrae, while regulated BMAT (rBMAT) is situated in the proximal regions of long bones and in spinal vertebrae [21]. cBMAT and rBMAT are not only anatomically distinct but also show different responses to age, weight, endocrine factors and medical interventions. In brief, cBMAT appears in the early postnatal period, histologically resembles WAT, and mostly does not increase or decrease in response to external stimuli or pathophysiological changes. Conversely rBMAT develops after cBMAT, is interspersed with haematopoietic cells and increases or decreases in various conditions (reviewed [18, 21]). Adipocytes within cBMAT and rBMAT were recently shown to have different metabolic functions, with cBMAT being more resistant to lipolytic stimuli [16•]. Thus, cBMAT and rBMAT may have distinct impacts on metabolic homeostasis.

Beyond this potential heterogeneity between BMAT subtypes, a broader question is whether BMAT function overlaps with that of WAT or BAT. Establishing the pathophysiological roles of BMAT will be crucial to determine whether it represents a new target for disease treatment (reviewed in [22]). Histologically, BMAT adipocytes typically resemble those in WAT; however, whether BMAT is WAT- or BAT-like remains a subject of debate. Indeed, it has been reported that BM has a mixed BAT/WAT population of adipocytes. Krings et al. transcriptionally analysed whole tibiae, revealing detectable expression of BAT markers including Prdm16, Dio2 and Pgc1 $\alpha$ [23]. Furthermore, they found that aged diabetic mice showed decreased expression of BAT markers in whole tibiae, suggesting that BMAT function changes with ageing and diabetes. Most interestingly, administration of rosiglitazone, a synthetic agonist for adipocyte-specific PPAR $\gamma$ and a potent insulin sensitiser, significantly increased both BAT (Ucp1, Pgc1 $\alpha$, Dio2, $\beta 3 A R$, Prdm16 and FoxC2) and WAT (Adipoq and Lep) markers in whole tibiae of normoglycemic mice, but not in diabetic mice [23]. More recently it has been reported that, compared with cBMAT, rBMAT is characterised by elevated expression of beige fat markers, including Ucp1 [24]. However, we have shown that Ucpl expression in whole tibiae is 10,000 - to 25,000-fold lower than in BAT [25]. This level of expression is similar to that observed by Krings et al. and clearly argues against BAT-like functions of BMAT. However, these studies also highlight the technical limitations of using whole bones to represent BMAT. Efficient isolation of a pure population of adipocytes from the bone marrow is technically very difficult, though methods to achieve this have been reported [26]. Advanced imaging approaches are also allowing BMAT-specific analysis, with 
$3 \mathrm{D}$ electron microscopy recently revealing a dense mitochondrial network within BM adipocytes [27].

This latter observation supports the possibility that BM adipocytes may have some brown- or beige-adipocyte-like characteristics. Consistent with this, brown-like adipocytes were observed in a BM core biopsy taken from a 74-yearold man with untreated lymphoplasmacytic lymphoma. The authors reported that these adipocytes were UCP1positive and largely separated from the surrounding marrow, suggesting that the observed "BAT" may be an incidental intraosseous hibernoma [22, 28]. Furthermore, 18FFDG-PET/CT imagining of healthy young human subjects, with or without cold stimuli, identified cold-stimulated $18 \mathrm{~F}-\mathrm{FDG}$ uptake in vertebral bone marrow that significantly correlated with $18 \mathrm{~F}-\mathrm{FDG}$ uptake into BAT [29]. The authors further identified expression of UCP1 and PRDM16 in BM from two male subjects, while histological assessment of vertebral BM from 3-week-old mice highlighted the presence of multilocular, brown-like adipocytes that were positive for UCP1. Taken together, these data suggest the presence of functional brown adipocytes in vertebral BM of mammals. The authors suggest that the presence of brown adipocytes in the BM seems plausible given that Myf5-positive cells emerge at the juxtaspinal, prospectively paravertebral, regions within somites [30, 31 , and it has been well documented that BAT is derived from Myf5-positive myoblastic cells [32].

A recent study provided further evidence for a mixed BAT/ WAT phenotype of BMAT both in vitro and in vivo. The authors showed that treatment of BM mesenchymal stromal cells or stromal ST2 cells with triiodothyronine or a thyroid hormone receptor beta-specific agonist $(G C-1)$ significantly increased expression of brown and beige fat markers. Furthermore, administration of $G C-1$ in vivo in thyroid hormone-deficient $\left(T s r^{-/}\right)$mice showed a 149-fold increase in Ucpl expression in skeletal tissue (femoral and tibial epiphyses). Whether this translates into detectable UCP1 protein expression remains to be confirmed; however, these data suggest not only that thyroid hormone induces the expression of BAT genes in mouse BMAT but, importantly, that like WAT, BMAT has the potential to beige [33].

Murine tracer models are crucial in search of the origin of BMAT. In contrast with the above data, recent research has shown that the origin of BMAT is likely to be distinct to that of WAT and BAT. WAT is derived from Myf5 $/ \mathrm{Pax} 7^{-}$progenitors, while BAT is derived from $\mathrm{Myf} 5^{+} / \mathrm{Pax} 7^{+}$progenitors [14••, 32, 34]. Strikingly, BM adipocytes are also derived from progenitors that express Osterix. Once thought to be osteoblast-specific, Osterix is a transcription factor that acts downstream of Runx2/Cbfa1 and is required for osteoblast differentiation [35]. Lineage tracing studies using Prx1Cre:mT/mG and Osx1-Cre:mT/mG showed that tibial and femoral BM adipocytes were traced in Prx1-Cre:mT/mG mice as well as endosteum osteocytes, articular chondrocytes and inguinal WAT. Furthermore, in Osx 1-Cre:mT/mG mice, tracing occurred only in adipocytes in BMAT, and not those in WAT or BAT depots, suggesting that BMAT arises from a mesenchymal-osteogenic lineage [36-38] (Comprehensively reviewed in [14••]). Further unpublished lineage tracing studies have shown that insulin signalling is not required for lipid accumulation in BMAT, but is required in WAT, providing evidence for the functional differences in regulation of adipose depots $[14 \bullet \bullet]$.

\section{BMAT Autocrine, Paracrine and Endocrine Interactions}

\section{Sexual Dimorphism}

The distribution of WAT and BAT shows a clear sexual dimorphism $[39,40]$ that seems to also apply to BMAT. We have found that female mice tend to have a higher volume of rBMAT in the proximal tibial diaphysis [41], whereas in humans BM fat is higher in males than in females, at least in younger adults [42]. To further explore such sex differences, Lecka-Czernik et al. investgiated the impact of sex steroids on BMAT [24]. While no sexual divergence in the volume and transcriptional profile of distal BMAT was observed, ovariectomy led to increased BMAT, increased Adipoq (adiponectin) and decreased beige fat gene markers. Orchidectomy in males also tended to increase BMAT, consistent with previous observations that testosterone can decrease BMAT in female rats [43]. However, unlike ovariectomy, orchidectomy did not change expression of Adipoq or beige fat gene markers [24]. Thus, males and females may differ in how their sex steroid deficiency affects BMAT formation and endocrine function [24].

In humans, the impact of testosterone on BMAT remains to be established, but the effects of oestrogen are similar to those observed in rodent studies. For example, Limonard et al. used MRI to measure vertebral BM fat in postmenopausal women before, during, and following a two-week treatment with 17- $\beta$ estradiol. Even in such a short timescale, this treatment was found to rapidly decrease the BM fat fraction [44]. Consistent with this, in younger adults vertebral BM fat tends to be higher in males than in females, whereas, post-menopause, females have greater vertebral BM fat content [42]. Thus, oestrogen clearly has a profound ability to suppress BMAT formation, which likely contributes to the sex differences in BMAT content across the lifecourse. More recent studies suggest that BMAT is also regulated by follicle-stimulating hormone (FSH). Specifically, mice that underwent ovariectomy and were then given an FSH antibody had decreased BMAT volume coupled with decreased fat mass and the production of UCP1-positive adipose tissue [45]. Thus, beyond oestrogen 
and testosterone, it will be important to determine if other sex hormones can also regulate BMAT formation and function in humans.

\section{Adiponectin}

BMAT is known to increase in caloric restriction (CR), contributing to increases in circulating adiponectin [46, 47]. Adiponectin is the most abundant adipokine in the circulation and can be used as a clinical biomarker for early detection of conditions such as type 2 diabetes, cardiovascular diseases, and certain cancers. Although we have recently reviewed this elsewhere [47], many questions remain regarding adiponectin secretion from BMAT and how this is altered by disease. For example, recent human data suggest that adiponectin may regulate the relationship between BMAT and insulin sensitivity in obese and non-obese premenopausal women [48]. It remains unclear if adiponectin secretion from BMAT directly influences cardiac function or the risk of cardiovascular disease. Studies in rats showed that bone marrow and adipose mesenchymal stem cells attenuated cardiac fibrosis [49]. However, far more research effort is required to understand if BMAT directly impacts cardiac function or impacts other tissues, such as the liver and pancreas, that are known to be targeted by adiponectin [50].

\section{Bone Trauma and Pathology}

Given the close proximity of BMAT to the bone, researchers have suggested that BMAT directly regulates bone metabolism. In the last decade, bone has emerged as a highly metabolic organ that contributes to the regulation of whole-body metabolism [51]. Indeed, bone has the capability to regenerate without scar formation following mechanical and structural failure. This occurs typically by secondary endochondral healing, which consists of both endochondral and intramembranous ossification. The process of secondary endochondral healing begins with haematoma formation; then an acute inflammatory response with pro-inflammatory signalling; primary callus formation (soft callus), which undergoes revascularisation and calcification to form the hard callus; and finally bone remodelling [52]. This process of fracture healing is highly metabolically demanding and requires the cooperation between different cell types, as recently reviewed elsewhere [53]. BM adipocytes secrete adipokines (e.g. adiponectin), cytokines (e.g. RANKL), and free fatty acids that act to promote bone resorption, haematopoietic recovery and supply energy. Indeed, BMAT has been reported to be increased in subjects with prevalent vertebral fracture $[54,55]$ and prevalent vertebral deformities [56]. Despite recent efforts, it remains unclear why BMAT increases in fracture and, specifically, why there is an intricate relationship between bone and BMAT during bone pathology. Moreover, in cases of failed bone regeneration, such as non-union fracture, it remains unclear if BMAT has a positive or negative impact on bone healing [57]. Most recently, Ambrosi et al. elegantly showed that BMAT exerts direct negative effects on bone healing and haematopoiesis in mouse models, with BM adipocytes secreting dipeptidyl peptidase-4 (DPP4) to inhibit fracture repair [58]. Given that DPP4 is a target of anti-diabetic therapies, this finding raises the intriguing possibility that BMAT-derived DPP4 might impact not only skeletal remodelling, but also systemic insulin resistance.

Osteoarthritis (OA) is a heterogeneous disease that leads to the progressive loss of normal joint function and related subchondral bone changes. OA is the most common form of arthritis and represents the world's leading cause of physical disability in adults. At a time when the population is ageing and the prevalence of obesity is increasing, there has never been a greater need for the prevention of OA. Currently, OA is routinely managed therapeutically and patients are offered physiotherapy [59]. Traditionally, OA was considered to be a disease of the cartilage, but more recently has been shown to affect the entire joint, including the bone, synovium, tendons, and muscles [60]. The location of BMAT suggests that BM adipocytes may play a role in the pathology of OA. A recent study found increased BMAT in postmenopausal women with both OA and osteoporosis (OP), and the authors suggested that a subgroup of OA subjects with elevated BMAT may have a high risk of developing OP [61].

\section{Interaction of BMAT with Bone Cells}

BMAT has recently been shown to be responsive to parathyroid hormone and to secrete receptor activator of nuclear factor kappa-B ligand (RANKL), a key regulator of osteoclast differentiation and activation [26]. This suggests that BMAT exhibits unique osteo-resorptive characteristics. Furthermore, murine models with decreased sclerostin (SOST) have significantly decreased BMAT [62], suggesting that BMAT formation is governed directly by osteocytes, which secrete SOST. Currently, there is much interest in anti-SOST therapy for treatment of OP. This is driving a greater consideration of the clinical implications of BMAT, which should help to further our knowledge of this complex adipose depot $[62,63]$. In murine models and human patients with low bone mineral density (BMD) and bone formation, BMAT has been shown to be elevated (reviewed $[64 \bullet \bullet, 65]$ ). Mice with a loss of function mutation in the Dock7 gene, which results in low BMD and reduced bone formation, have very few osteoblasts but BMAT is increased 3.5-fold compared to wild-type controls. However, it is important to highlight that other studies have not found an inverse relationship between BMD and BMAT. For example, BMAT was significantly increased following 12 weeks of high-fat diet feeding in mice, while BMD was unchanged [66]. Furthermore, $\mathrm{C} 3 \mathrm{H} / \mathrm{HeJ}$ mice have increased 
bone mass and BMAT compared to C57BL/6 mice [67], and we have shown that during $\mathrm{CR}$ in rabbits, bone loss can occur independently of BMAT expansion [41].

\section{Metastasis, Myeloma and BMAT}

The interplay between tumour cells, osteoclasts and osteoblasts is well documented, but despite occupying 50 to $70 \%$ of the total $\mathrm{BM}$ volume, the relationship between BMAT, multiple myeloma, and metastasis of breast and prostate has only just begun to be understood. While beyond the scope of this review, others have recently provided elegant overviews of the growing evidence linking BMAT to tumour growth and the development of associated bone disease [68-71].

\section{Technological Advances to Assess BMAT Quantity and Metabolic Function}

As reviewed elsewhere in this issue, techniques for BMAT imaging are improving and expanding. Standard histological approaches, such as haematoxylin and eosin staining of paraffin-embedded sections, have been used routinely to detect adipocytes within BM. More recently, osmium tetroxide staining followed by micro-computed tomography $(\mu \mathrm{CT})$ has been used to visualise and quantify BMAT in situ [72]. New $\mu \mathrm{CT}$ contrast agents are currently being developed to assess BMAT, vasculature and nerves without the requirement for time-consuming decalcification. The most recent of these stains, for use in contrast-enhanced microfocus computed tomography (CE-CT), is a Hafnium-based Wells-Dawson polyoxometalate (Hf-POM) [73, 74]. Hf-POM has been validated in murine long bones and provides the researcher with a 3D representation of the mineralised bone, vasculature and BMAT. These developments in contrast agents allow novel insights into the interaction between the bone, vasculature and BMAT. However, as for osmium $\mu \mathrm{CT}$, specialist highresolution $\mathrm{CT}$ scanners are required.

One relatively simple technique has been developed by the Horowitz laboratory, allowing BMAT to be visualised ex vivo by confocal microscopy (described in [14••]). Briefly, the BMAT is extracted from long bones by using a needle to punch through the length of the diaphysis. This BMAT plug is then gently ejected onto a slide, immersed in Fluoromount$\mathrm{G}$ (eBioscience), cover-slipped and then visualised. This method does not affect intrinsic fluorescence (e.g. $\mathrm{mT} / \mathrm{mG}$ reporter mice) and allows staining of neutral lipids within the BM adipocytes.

Studies in human subjects routinely use $\mathrm{CT}$ and magnetic resonance spectroscopy (MRS) and imaging (MRI) methods to measure BMAT. A comprehensive review of these techniques can be found elsewhere in this issue; however, it is worth highlighting the developments in BMAT imaging that are particularly relevant to its metabolic characteristics and functions. For example, ex vivo high-resolution magic angle spinning (HRMAS) proton nuclear magnetic resonance $\left({ }^{1} \mathrm{H}\right.$ NMR) spectroscopy has recently been used in humans to determine the (un)saturation level of fatty acids in BMAT [75]. A novel, dual-energy computed tomography (DECT) method has also been described to assess both BMAT and marrowcorrected volumetric BMD (mcvBMD) [76]. Hopefully, these developments in new clinical techniques will allow researchers to more accurately assess BMAT's lipid composition and relationship with skeletal parameters.

Finally, imaging studies are beginning to shed light on the metabolic functions of BMAT. Positron emission tomography-computed tomography (PETCT) is a non-invasive technique allowing the visualisation of biological processes. Most simply, compounds are radiolabelled with positron-emitting radioisotopes (e.g. ${ }^{11} \mathrm{C},{ }^{15} \mathrm{O}$, and ${ }^{18} \mathrm{~F}$ ). These radiolabelled compounds emit positrons which annihilate with electrons and produce two annihilation photons that travel in opposite directions and are detected by the PET scanner. Upon detection, the PETCT scanner uses various algorithms and attenuation correction factors to hybridise the PET data with the CT images, allowing the user to visualise and analyse the anatomical locations of the tracer. PET imaging can be conducted either dynamically or statically. Clinically, static imaging is most common as dynamic analysis requires kinetic modelling, which is complex and time consuming [77]. The most commonly used radiotracer is ${ }^{18} \mathrm{~F}$-fluorodeoxyglucoe $\left({ }^{18} \mathrm{~F}\right.$-FDG), a glucose analogue that is actively transported into the cell by glucose transporters. After import, ${ }^{18}$ F-FDG can be phosphorylated by hexokinase to form 2-deoxyglucose-6-phosphate; however, unlike endogenous glucose, once phosphorylated ${ }^{18}$ F-FDG is unable to continue along the glycolytic pathway and instead accumulates in the cell as ${ }^{18} \mathrm{~F}$-labelled 2deoxyglucose-6-phosphate. This intracellular accumulation of ${ }^{18} \mathrm{~F}$ allows the user to calculate the standardised uptake value (SUV, the concentration of radioactivity in a specific anatomic region, normalised to body weight and the injected dose of the radiotracer), which allows for the quantification of glucose utilisation, commonly in sites of inflammation, tissue repair and cancer [78]. One study in humans assessed ${ }^{18}$ F-FDG uptake into femoral and vertebral $B M$ during a hyperinsulinaemic-euglycaemic clamp, the gold-standard in assessing insulin sensitivity [15]. This revealed that insulin sensitivity in femoral BM, but not in vertebral BM, correlates with whole-body insulin sensitivity and is improved by exercise. However, it is unclear if this reflects insulin action in BMAT or in other BM components. Indeed, in another study this group used ${ }^{18} \mathrm{~F}$-FDG PET/CT, combined with MRI analysis of BMAT, to further characterise BMAT metabolic functions. They found that vertebral BM uptake was inversely associated with BMAT content in both diabetic and healthy 
pigs [79]. This suggests that BMAT itself may not be highly insulin responsive. In addition to ${ }^{18} \mathrm{~F}-\mathrm{FDG}$, other tracers that target, for example, translocator protein $18 \mathrm{kDa}$ (TSPO) may be useful in dissecting BMAT function. TSPO is an outer mitochondrial membrane transporter that is downregulated in both WAT and BAT during obesity [80] and can be used to image human BAT mass under thermoneutral conditions [81]. Therefore, TSPO may be useful to further understand the phenotypic WAT/BAT properties of BMAT. Clearly, $\mathrm{PET} / \mathrm{CT}$ holds great potential to improve our understanding of the metabolic functions of BMAT and their contribution to systemic energy homeostasis.

\section{Conclusions}

Though still dwarfed by research into WAT and BAT, BMAT is attracting increasing attention from biomedical researchers around the globe. Indeed, 2017 saw the creation of the International Bone Marrow Adiposity Society (http://bmasociety.org/), which aims to further our knowledge of this intriguing tissue. Thus, we are beginning to learn about the importance of BMAT both within and beyond the bone, allowing us to better appreciate the role of BMAT in normal physiology and disease. These advances will hopefully allow us to develop and explore new therapeutic agents to treat bone disease, metabolic disease and skeletal tumours, including both haematological malignancies and metastases from elsewhere. In order for this encouraging progression to continue, new murine models must be created to determine (1) if the physiological location of BMAT affects its physiological role; (2) if different populations of adipocytes are present within BMAT; and (3) if the role of BMAT changes during ageing and disease. In addition, as methods for clinical BMAT measurement become better established, it will be important to apply these more routinely so that BMAT content can be assessed across broader populations. Such information should help to better resolve the physiological and pathological functions of this relatively neglected adipose subtype. Ultimately, now is a very exciting time to be studying BMAT: while there is much more still to learn, research in this field is burgeoning. Thus, we look forward to many key discoveries in the years ahead.

\section{Compliance with Ethical Standards}

Conflict of Interest Karla J Suchacki declares no conflicts of interest.

William P Cawthorn reports grants from The Medical Research Council (UK), during the conduct of the study.

Human and Animal Rights and Informed Consent This article does not contain any studies with human or animal subjects performed by any of the authors.
Open Access This article is distributed under the terms of the Creative Commons Attribution 4.0 International License (http:// creativecommons.org/licenses/by/4.0/), which permits unrestricted use, distribution, and reproduction in any medium, provided you give appropriate credit to the original author(s) and the source, provide a link to the Creative Commons license, and indicate if changes were made.

\section{References}

Papers of particular interest, published recently, have been highlighted as:

- Of importance

•- Of major importance

1. Berry DC, Stenesen D, Zeve D, Graff JM. The developmental origins of adipose tissue. Development (Cambridge, England). 2013;140(19):3939-49. https://doi.org/10.1242/dev.080549.

2. Saely $\mathrm{CH}$, Geiger K, Drexel H. Brown versus white adipose tissue: a mini-review. Gerontology. 2012;58(1):15-23. https://doi.org/10. $1159 / 000321319$.

3. Yang X, Jiang Y, Han G, Shi Y, Zhou S, Ni F, et al. Altered adiposederived stem cell characteristics in macrodactyly. Sci Rep. 2017;7(1):11090. https://doi.org/10.1038/s41598-017-11666-3.

4. Robinson L, Micali N, Misra M. Eating disorders and bone metabolism in women. Curr Opin Pediatr. 2017;29(4):488-96. https://doi. org/10.1097/mop.0000000000000508.

5. Bastos CM, Araujo IM, Nogueira-Barbosa MH, Salmon CEG, de Paula FJA, Troncon LEA. Reduced bone mass and preserved marrow adipose tissue in patients with inflammatory bowel diseases in long-term remission. Osteoporos Int: J Established Result Coop Between Eur Found Osteoporos Natl Osteoporos Found USA. 2017;28(7):2167-76. https://doi.org/10.1007/s00198-017-4014-3.

6. Yu NY, Wolfson T, Middleton MS, Hamilton G, Gamst A, Angeles $\mathrm{JE}$, et al. Bone marrow fat content is correlated with hepatic fat content in paediatric non-alcoholic fatty liver disease. Clin Radiol. 2017;72(5):425-e9-.e14. https://doi.org/10.1016/j.crad.2016.11. 017.

7. Yu EW, Greenblatt L, Eajazi A, Torriani M, Bredella MA. Marrow adipose tissue composition in adults with morbid obesity. Bone. 2016;97:38-42. https://doi.org/10.1016/j.bone.2016.12.018.

8. Whitney DG, Singh H, Miller F, Barbe MF, Slade JM, Pohlig RT, et al. Cortical bone deficit and fat infiltration of bone marrow and skeletal muscle in ambulatory children with mild spastic cerebral palsy. Bone. 2017;94:90-7. https://doi.org/10.1016/j.bone.2016.10. 005 .

9. de Araujo IM, Salmon CE, Nahas AK, Nogueira-Barbosa MH, Elias J Jr, de Paula FJ. Marrow adipose tissue spectrum in obesity and type 2 diabetes mellitus. Eur J Endocrinol. 2017;176(1):21-30. https://doi.org/10.1530/eje-16-0448.

10. Scheller EL, Khoury B, Moller KL, Wee NK, Khandaker S, Kozloff $\mathrm{KM}$, et al. Changes in skeletal integrity and marrow adiposity during high-fat diet and after weight loss. Front Endocrinol. 2016;7: 102. https://doi.org/10.3389/fendo.2016.00102.

11. Sheu Y, Amati F, Schwartz AV, Danielson ME, Li X, Boudreau R, et al. Vertebral bone marrow fat, bone mineral density and diabetes: the osteoporotic fractures in men (MrOS) study. Bone. 2017;97: 299-305. https://doi.org/10.1016/j.bone.2017.02.001.

12. Yu EW, Greenblatt L, Eajazi A, Torriani M, Bredella MA. Marrow adipose tissue composition in adults with morbid obesity. Bone. 2017;97:38-42. https://doi.org/10.1016/j.bone.2016.12.018. 
13. Moorthi RN, Fadel W, Eckert GJ, Ponsler-Sipes K, Moe SM, Lin C. Bone marrow fat is increased in chronic kidney disease by magnetic resonance spectroscopy. Osteoporos Int: J Established Result Coop Between Eur Found Osteoporos Natl Osteoporos Found USA. 2015;26(6):1801-7. https://doi.org/10.1007/s00198-015-3064-7.

14.• Horowitz MC, Berry R, Holtrup B, Sebo Z, Nelson T, Fretz JA, et al. Bone marrow adipocytes. Adipocyte. 2017;6:1-12. https:// doi.org/10.1080/21623945.2017.1367881. Extensive review regarding BMAT, providing personal and very detailed insights.

15. Huovinen V, Bucci M, Lipponen H, Kiviranta R, Sandboge S, Raiko J, et al. Femoral bone marrow insulin sensitivity is increased by resistance training in elderly female offspring of overweight and obese mothers. PLoS One. 2016;11(9):e0163723. https://doi.org/ 10.1371/journal.pone.0163723.

16. Scheller EL, Khandaker S, Learman BS, Cawthorn WP, Anderson LM, Pham HA, et al. Bone marrow adipocytes resist lipolysis and remodeling in response to beta-adrenergic stimulation. Bone. 2018; https://doi.org/10.1016/j.bone.2018.01.016. The authors elegeantly show that MAT has the capacity to respond to $\beta$-adrenergic stimuli.

17. Hindorf C, Glatting G, Chiesa C, Linden O, Flux G. EANM dosimetry committee guidelines for bone marrow and whole-body dosimetry. Eur J Nucl Med Mol Imaging. 2010;37(6):1238-50. https://doi.org/10.1007/s00259-010-1422-4.

18. Li Z, Hardij J, Bagchi DP, Scheller EL, MacDougald OA. Development, regulation, metabolism and function of bone marrow adipose tissues. Bone. 2018; https://doi.org/10.1016/j.bone.2018. 01.008 .

19. Blebea JS, Houseni M, Torigian DA, Fan C, Mavi A, Zhuge Y, et al. Structural and functional imaging of normal bone marrow and evaluation of its age-related changes. Semin Nucl Med. 37(3):185-94. https://doi.org/10.1053/j.semnuclmed.2007.01.002.

20. Bredella MA, Torriani M, Ghomi RH, Thomas BJ, Brick DJ, Gerweck AV, et al. Vertebral bone marrow fat is positively associated with visceral fat and inversely associated with IGF-1 in obese women. Obesity (Silver Spring, Md). 2011;19(1):49-53. https:// doi.org/10.1038/oby.2010.106.

21. Scheller EL, Doucette CR, Learman BS, Cawthorn WP, Khandaker $\mathrm{S}$, Schell B, et al. Region-specific variation in the properties of skeletal adipocytes reveals regulated and constitutive marrow adipose tissues. Nat Commun. 2015;6:7808. https://doi.org/10.1038/ ncomms 8808 .

22. Hardouin P, Rharass T, Lucas S. Bone marrow adipose tissue: to be or not to be a typical adipose tissue? Front Endocrinol. 2016;7:85. https://doi.org/10.3389/fendo.2016.00085.

23. Krings A, Rahman S, Huang S, Lu Y, Czernik PJ, Lecka-Czernik B. Bone marrow fat has brown adipose tissue characteristics, which are attenuated with aging and diabetes. Bone. 2012;50(2):546-52. https://doi.org/10.1016/j.bone.2011.06.016.

24. Lecka-Czernik B, Stechschulte LA, Czernik PJ, Sherman SB, Huang S, Krings A. Marrow adipose tissue: skeletal location, sexual dimorphism, and response to sex steroid deficiency. Front Endocrinol. 2017;8:188. https://doi.org/10.3389/fendo.2017. 00188.

25. Sulston RJ, Cawthorn WP. Bone marrow adipose tissue as an endocrine organ: close to the bone? Horm Mol Biol Clin Invest. 2016;28(1):21-38. https://doi.org/10.1515/hmbci-2016-0012.

26. Fan Y, Hanai JI, Le PT, Bi R, Maridas D, DeMambro V, et al. Parathyroid hormone directs bone marrow mesenchymal cell fate. Cell Metab. 2017;25(3):661-72. https://doi.org/10.1016/j.cmet. 2017.01.001.

27. Robles H, Park S, Joens MS, Fitzpatrick JAJ, Craft CS, Scheller EL. Characterization of the bone marrow adipocyte niche with three-dimensional electron microscopy. Bone. 2018; https://doi. org/10.1016/j.bone.2018.01.020.
28. Chapman J, Vega F. Incidental brown adipose tissue in bone marrow biopsy. Blood. 2017;130(7):952. https://doi.org/10.1182/ blood-2017-04-778563.

29. Nishio M, Yoneshiro T, Nakahara M, Suzuki S, Saeki K, Hasegawa $\mathrm{M}$, et al. Production of functional classical brown adipocytes from human pluripotent stem cells using specific hemopoietin cocktail without gene transfer. Cell Metab. 2012;16(3):394-406. https://doi. org/10.1016/j.cmet.2012.08.001.

30. Cossu G, Kelly R, Tajbakhsh S, Di Donna S, Vivarelli E, Buckingham M. Activation of different myogenic pathways: myf5 is induced by the neural tube and MyoD by the dorsal ectoderm in mouse paraxial mesoderm. Development (Cambridge, England). 1996;122(2):429-37.

31. Braun T, Arnold HH. Myf-5 and myoD genes are activated in distinct mesenchymal stem cells and determine different skeletal muscle cell lineages. EMBO J. 1996;15(2):310-8.

32. Seale P, Bjork B, Yang W, Kajimura S, Chin S, Kuang S, et al. PRDM16 controls a brown fat/skeletal muscle switch. Nature. 2008;454(7207):961-7. https://doi.org/10.1038/nature07182.

33. Lindsey RC, Mohan S. Thyroid hormone acting via TRbeta induces expression of browning genes in mouse bone marrow adipose tissue. Endocrine. 2017;56(1):109-20. https://doi.org/10.1007/ s12020-017-1265-x.

34. Lepper C, Fan CM. Inducible lineage tracing of Pax7-descendant cells reveals embryonic origin of adult satellite cells. Genesis (New York, NY : 2000). 2010;48(7):424-36. https://doi.org/10.1002/dvg. 20630.

35. Nakashima K, Zhou X, Kunkel G, Zhang Z, Deng JM, Behringer $\mathrm{RR}$, et al. The novel zinc finger-containing transcription factor osterix is required for osteoblast differentiation and bone formation. Cell. 2002;108(1):17-29.

36. Sanchez-Gurmaches J, Hsiao WY, Guertin DA. Highly selective in vivo labeling of subcutaneous white adipocyte precursors with Prx1-Cre. Stem Cell Rep. 2015;4(4):541-50. https://doi.org/10. 1016/j.stemcr.2015.02.008.

37. Sanchez-Gurmaches J, Guertin DA. Adipocyte lineages: tracing back the origins of fat. Biochim Biophys Acta (BBA) - Mol Basis Dis. 2014;1842(3):340-51. https://doi.org/10.1016/j.bbadis.2013. 05.027.

38. Krueger KC, Costa MJ, Du H, Feldman BJ. Characterization of Cre recombinase activity for in vivo targeting of adipocyte precursor cells. Stem Cell Rep. 2014;3(6):1147-58. https://doi.org/10.1016/ j.stemcr.2014.10.009.

39. Kim SN, Jung YS, Kwon HJ, Seong JK, Granneman JG, Lee YH. Sex differences in sympathetic innervation and browning of white adipose tissue of mice. Biol Sex Differ. 2016;7:67. https://doi.org/ 10.1186/s13293-016-0121-7.

40. Fuente-Martín E, Argente-Arizón P, Ros P, Argente J, Chowen JA. Sex differences in adipose tissue: it is not only a question of quantity and distribution. Adipocyte. 2013;2(3):128-34. https://doi.org/ 10.4161/adip.24075.

41. Cawthorn WP, Scheller EL, Parlee SD, Pham HA, Learman BS, Redshaw CM, et al. Expansion of bone marrow adipose tissue during caloric restriction is associated with increased circulating glucocorticoids and not with hypoleptinemia. Endocrinology. 2016;157(2):508-21. https://doi.org/10.1210/en.2015-1477.

42. Griffith JF, Yeung DK, Ma HT, Leung JC, Kwok TC, Leung PC. Bone marrow fat content in the elderly: a reversal of sex difference seen in younger subjects. J Magn Reson Imaging : JMRI. 2012;36(1):225-30. https://doi.org/10.1002/jmri.23619.

43. Tamura N, Kurabayashi T, Nagata H, Matsushita H, Yahata T, Tanaka K. Effects of testosterone on cancellous bone, marrow adipocytes, and ovarian phenotype in a young female rat model of polycystic ovary syndrome. Fertil Steril. 2005;84(Suppl 2):127784. https://doi.org/10.1016/j.fertnstert.2005.06.017. 
44. Limonard EJ, Veldhuis-Vlug AG, van Dussen L, Runge JH, Tanck MW, Endert E, et al. Short-term effect of estrogen on human bone marrow fat. J Bone Miner Res : Off J Am Soc Bone Miner Res. 2015;30(11):2058-66. https://doi.org/10.1002/jbmr.2557.

45. Liu P, Ji Y, Yuen T, Rendina-Ruedy E, DeMambro VE, Dhawan S, et al. Blocking FSH induces thermogenic adipose tissue and reduces body fat. Nature. 2017;546(7656):107-12. https://doi.org/ 10.1038 /nature22342.

46. Cawthorn WP, Scheller EL, Learman BS, Parlee SD, Simon BR, Mori $\mathrm{H}$, et al. Bone marrow adipose tissue is an endocrine organ that contributes to increased circulating adiponectin during caloric restriction. Cell Metab. 2014;20(2):368-75. https://doi.org/10. 1016/j.cmet.2014.06.003.

47. Scheller EL, Burr AA, MacDougald OA, Cawthorn WP. Inside out: bone marrow adipose tissue as a source of circulating adiponectin. Adipocyte. 2016;5(3):251-69. https://doi.org/10.1080/21623945. 2016.1149269.

48. Ermetici F, Briganti S, Delnevo A, Cannao P, Leo GD, Benedini S, et al. Bone marrow fat contributes to insulin sensitivity and adiponectin secretion in premenopausal women. Endocrine. 2017;59:410-8. https://doi.org/10.1007/s12020-017-1349-7.

49. Fikry EM, Hassan WA, Gad AM. Bone marrow and adipose mesenchymal stem cells attenuate cardiac fibrosis induced by methotrexate in rats. J Biochem Mol Toxicol. 2017;31 https://doi.org/10. 1002/jbt.21970.

50. Turer AT, Scherer PE. Adiponectin: mechanistic insights and clinical implications. Diabetologia. 2012;55(9):2319-26. https://doi. org/10.1007/s00125-012-2598-x.

51. Suchacki KJ, Roberts F, Lovdel A, Farquharson C, Morton NM, MacRae VE, et al. Skeletal energy homeostasis: a paradigm of endocrine discovery. J Endocrinol. 2017;234(1):R67-79. https:// doi.org/10.1530/joe-17-0147.

52. Marsell R, Einhorn TA. The biology of fracture healing. Injury. 2011;42(6):551-5. https://doi.org/10.1016/j.injury.2011.03.031.

53. Loeffler J, Duda GN, Sass FA, Dienelt A. The metabolic microenvironment steers bone tissue regeneration. Trends Endocrinol Metab. 2018;29(2):99-110. https://doi.org/10.1016/j.tem.2017.11. 008.

54. Justesen J, Stenderup K, Ebbesen EN, Mosekilde L, Steiniche T, Kassem M. Adipocyte tissue volume in bone marrow is increased with aging and in patients with osteoporosis. Biogerontology. 2001;2(3):165-71.

55. Schwartz AV, Sigurdsson S, Hue TF, Lang TF, Harris TB, Rosen $\mathrm{CJ}$, et al. Vertebral bone marrow fat associated with lower trabecular BMD and prevalent vertebral fracture in older adults. J Clin Endocrinol Metab. 2013;98(6):2294-300. https://doi.org/10.1210/ jc.2012-3949.

56. Wehrli FW, Hopkins JA, Hwang SN, Song HK, Snyder PJ, Haddad JG. Cross-sectional study of osteopenia with quantitative MR imaging and bone densitometry. Radiology. 2000;217(2):527-38. https://oi.org/10.1148/radiology.217.2.r00nv20527.

57. Schwartz AV. Marrow fat and bone: review of clinical findings. Front Endocrinol. 2015;6:40. https://doi.org/10.3389/fendo.2015. 00040.

58. Ambrosi TH, Scialdone A, Graja A, Gohlke S, Jank AM, Bocian C, et al. Adipocyte accumulation in the bone marrow during obesity and aging impairs stem cell-based hematopoietic and bone regeneration. Cell Stem Cell. 2017;20(6):771-84.e6. https://doi.org/10. 1016/j.stem.2017.02.009.

59. Neogi T. Clinical significance of bone changes in osteoarthritis. Ther Adv Musculoskelet Dis. 2012;4(4):259-67. https://doi.org/ 10.1177/1759720X12437354.

60. Fellows CR, Matta C, Zakany R, Khan IM, Mobasheri A. Adipose, bone marrow and synovial joint-derived mesenchymal stem cells for cartilage repair. Front Genet. 2016;7:213. https://doi.org/10. 3389/fgene.2016.00213.
61. Li G, Xu Z, Fan J, Yuan W, Zhang L, Hou L, et al. To assess differential features of marrow adiposity between postmenopausal women with osteoarthritis and osteoporosis using water/fat MRI. Menopause (New York, NY). 2017;24(1):105-11. https://doi.org/ 10.1097/gme.0000000000000732.

62. Fairfield H, Falank C, Harris E, Demambro V, McDonald M, Pettitt JA, et al. The skeletal cell-derived molecule sclerostin drives bone marrow adipogenesis. J Cell Physiol. 2018;233(2):1156-67. https:// doi.org/10.1002/jep.25976.

63. Fairfield H, Rosen CJ, Reagan MR. Connecting bone and fat: the potential role for Sclerostin. Curr Mol Biol Rep. 2017;3(2):114-21. https://doi.org/10.1007/s40610-017-0057-7.

64.• Ambrosi TH, Schulz TJ. The emerging role of bone marrow adipose tissue in bone health and dysfunction. $\mathrm{J}$ Mol Med (Berlin, Germany). 2017;95(12):1291-301. https://doi.org/10. 1007/s00109-017-1604-7. Informative reivew regaiding the current understanding of BMAT biology in bone health and dysfunction.

65. Grandl G, Wolfrum C. Adipocytes at the core of bone function. Cell Stem Cell. 2017;20(6):739-40. https://doi.org/10.1016/j.stem. 2017.05.008.

66. Doucette CR, Horowitz MC, Berry R, MacDougald OA, Anunciado-Koza R, Koza RA, et al. A high fat diet increases bone marrow adipose tissue (MAT) but does not Alter trabecular or cortical bone mass in C57BL/6J mice. J Cell Physiol. 2015;230(9):2032-7. https://doi.org/10.1002/jcp.24954.

67. Fazeli PK, Horowitz MC, MacDougald OA, Scheller EL, Rodeheffer MS, Rosen CJ, et al. Marrow fat and bone - new perspectives. J Clin Endocrinol Metab. 2013;98(3):935-45. https:// doi.org/10.1210/jc.2012-3634.

68. Morris EV, Edwards CM. The role of bone marrow adipocytes in bone metastasis. J Bone Oncol. 2016;5(3):121-3. https://doi.org/ 10.1016/j.jbo.2016.03.006.

69. Morris EV, Edwards CM. Bone marrow adipose tissue: a new player in cancer metastasis to bone. Front Endocrinol. 2016;7:90. https://doi.org/10.3389/fendo.2016.00090.

70. Chkourko Gusky H, Diedrich J, MacDougald OA, Podgorski I. Omentum and bone marrow: how adipocyte-rich organs create tumour microenvironments conducive for metastatic progression. Obes Rev : Off J Int Assoc Study of Obes. 2016;17(11):1015-29. https://doi.org/10.1111/obr.12450.

71. Soley L, Falank C, Reagan MR. MicroRNA transfer between bone marrow adipose and multiple myeloma cells. Curr Osteoporos Rep. 2017;15(3):162-70. https://doi.org/10.1007/s11914-017-0360-5.

72. Scheller EL, Troiano N, Vanhoutan JN, Bouxsein MA, Fretz JA, Xi $\mathrm{Y}$, et al. Use of osmium tetroxide staining with microcomputerized tomography to visualize and quantify bone marrow adipose tissue in vivo. Methods Enzymol. 2014;537:123-39. https://doi.org/10. 1016/b978-0-12-411619-1.00007-0.

73. Coutel X, Olejnik C, Marchandise P, Delattre J, Behal H, Kerckhofs $\mathrm{G}$, et al. A novel microCT method for bone and marrow adipose tissue alignment identifies key differences between mandible and tibia in rats. Calcif Tissue Int. 2018; https://doi.org/10.1007/ s00223-018-0397-1.

74. Kerckhofs G, Stegen S, van Gastel N, Sap A, Falgayrac G, Penel G, et al. Simultaneous three-dimensional visualization of mineralized and soft skeletal tissues by a novel microCT contrast agent with polyoxometalate structure. Biomaterials. 2018;159:1-12. https:// doi.org/10.1016/j.biomaterials.2017.12.016.

75. Li X, Shet K, Xu K, Rodriguez JP, Pino AM, Kurhanewicz J, et al. Unsaturation level decreased in bone marrow fat of postmenopausal women with low bone density using high resolution magic angle spinning (HRMAS) 1H NMR spectroscopy. Bone. 2017;105:8792. https://doi.org/10.1016/j.bone.2017.08.014.

76. Arentsen L, Hansen KE, Yagi M, Takahashi Y, Shanley R, McArthur A, et al. Use of dual-energy computed tomography to 
measure skeletal-wide marrow composition and cancellous bone mineral density. J Bone Miner Metab. 2017;35(4):428-36. https:// doi.org/10.1007/s00774-016-0796-1.

77. Farwell MD, Pryma DA, Mankoff DA. PET/CT imaging in cancer: current applications and future directions. Cancer. 2014;120(22): 3433-45. https://doi.org/10.1002/cncr.28860.

78. CD Rajadhyaksha, JA Parker, L Barbaras, VH Gerbaudo Normal and benign pathological findings in 18FDG-PET and PET/CT: an interactive web based image Atlas. Harvard Medical School, Harvard Medical School. http://www.med.harvard.edu/JPNM/ chetan/basics/basics.html. Accessed 05/09/2017.

79. Huovinen V, Saunavaara V, Kiviranta R, Tarkia M, Honka H, Stark $\mathrm{C}$, et al. Vertebral bone marrow glucose uptake is inversely associated with bone marrow fat in diabetic and healthy pigs: [(18)F]FDG-PET and MRI study. Bone. 2014;61:33-8. https:// doi.org/10.1016/j.bone.2013.12.022.

80. Thompson MM, Manning HC, Ellacott KLJ. Translocator protein $18 \mathrm{kDa}$ (TSPO) is regulated in white and brown adipose tissue by obesity. PLoS One. 2013;8(11):e79980. https://doi.org/10.1371/ journal.pone.0079980.

81. Ran C, Albrecht DS, Bredella MA, Yang J, Yang J, Liang SH, et al PET imaging of human brown adipose tissue with the TSPO tracer [(11)C]PBR28. Mol Imag Biol : MIB : Off Publ Acad Mol Imag. 2017;20:188-93. https://doi.org/10.1007/s11307-017-1129-z. 